\title{
The relationship between dendritic branch dynamics and CPEB-labeled RNP granules captured in vivo
}

\author{
Jennifer E. Bestman and Hollis T. Cline* \\ Department of Cell Biology, The Scripps Research Institute, La Jolla, CA, USA
}

\section{Edited by:}

Liqun Luo, Stanford University, USA

Reviewed by:

R. Suzanne Zukin, Albert Einstein

College of Medicine, USA

Claudia Bagni, Catholic University of

Leuven Medical School, Belgium

\section{${ }^{*}$ Correspondence:}

Hollis T. Cline, Department of Cell

Biology, The Scripps Research Institute, 10550 North Torrey Pines Road, ICND

216, La Jolla, CA 92037, USA.

e-mail: cline@scripps.edu
Cytoplasmic Polyadenylation Element Binding protein (CPEB) is an RNA binding protein involved in dendritic delivery of mRNA and activity-dependent, polyadenylation-induced translation of mRNAs in the dendritic arbor. CPEB affects learning and memory and impacts neuronal morphological and synaptic plasticity. In neurons, CPEB is concentrated in ribonucleoprotein (RNP) granules that distribute throughout the dendritic arbor and localize near synapses, suggesting that the trafficking of RNP granules is important for CPEB function. We tagged full-length CPEB and an inactive mutant CPEB with fluorescent proteins, then imaged rapid dendritic branch dynamics and RNP distribution using two-photon time-lapse microscopy of neurons in the optic tectum of living Xenopus laevis tadpoles. Though the inactive CPEB mutant transports mRNA in the dendritic arbor, its expression interferes with CPEB-dependent translation because it is incapable of activity-triggered mRNA polyadenylation. In dendrites, the distributions of the active and inactive CPEB-containing RNP granules do not differ; the RNP granules are dense and their positions do not correlate with sites of rapid dendritic branch dynamics or the eventual fate of the dendritic branches. Because CPEB's sensitivity to activity-dependent signaling does not alter its dendritic distribution, it indicates that active sites in the dendritic arbor are not targeted for RNP granule localization. Nevertheless, inactive CPEB accumulates in granules in terminal dendritic branches, supporting the hypothesis that upon activation CPEB and its mRNA cargo are released from granules and are then available for dendritic translation.

Keywords: CPEB, dendrite, development, local protein synthesis, RNP granule, mRNA

\section{INTRODUCTION}

Spatially restricting mRNA distribution and translation to control the production of the proteins is a conserved mechanism associated with cellular polarization or compartmentalization with many examples across biology (Du et al., 2007; Besse and Ephrussi, 2008). In Saccharomyces cerevisiae, more than 24 transcripts are moved into the budding daughter cell (Shepard et al., 2003), including what is perhaps the most recognized example of mRNA localization, the transcription factor ASH1, which represses mating type switching to control the bud's fate (Cosma, 2004). Similarly, the fate of newly generated Drosophila melanogaster neurons is, in part, determined by the asymmetric distribution of mRNAs into the presumptive daughter cell during cell division (Du et al., 2007; Doe, 2008). Once differentiated, neurons are examples of the most morphologically complex cells known, in which, temporally- and spatially restricted protein synthesis from mRNA specifically localized to dendrites or axons contributes to the maintenance of this extreme polarization of neural structure and function (Sutton and Schuman, 2006).

To accomplish this precise spatial and temporal control of protein synthesis, mRNA is packaged into ribonucleoprotein (RNP) granules, which contain RNA binding proteins, the mRNAs that they target, elements of the translation apparatus, and motor proteins (Hirokawa, 2006; Kiebler and Bassell, 2006). In neurons, RNP granules are transported along microtubules (Sanchez-Carbente and Desgroseillers, 2008), and distribute throughout the cell body, dendritic arbor, and axons (Bramham and Wells, 2007; Lin and Holt, 2008). While RNP granules are transported along the dendritic cytoskeleton, translation of their mRNA cargo is repressed to prevent protein synthesis until it is triggered by local signals including synaptic neuronal activity (Sossin and DesGroseillers, 2006; Sanchez-Carbente and Desgroseillers, 2008). In dendrites, RNP granules often localize to synapses; they have been found in isolated synaptic compartments (synaptoneurosome preparations) (Weiler et al., 1997; Wu et al., 1998; Bagni et al., 2000), and light microscope immunohistochemical analyses have shown that RNP components colocalize with synaptic markers (Rook et al., 2000; Huang et al., 2002; Tiruchinapalli et al., 2003; Grooms et al., 2006). Although examples from other systems (e.g., regulation of axis specification in D. melanogaster embryos; St Johnston, 2005; Lecuyer et al., 2007) clearly demonstrate that the control of mRNA localization produces precise, spatially discrete sites of protein synthesis, the spatial range over which local protein synthesis from RNP granule components affects neuronal function is not clear.

Specific mRNAs are thought to be selected and coassembled into RNP granules (Mingle et al., 2005; Carson et al., 2008; Lange et al., 2008), suggesting that RNP granules act as self-sufficient "posttranscriptional operons" that temporally and spatially coordinate the translation of functionally related mRNAs (Moore, 2005; Keene, 2007; Hogan et al., 2008). Because many of the mRNAs isolated from dendrites and contained in RNP granules encode proteins that are thought to regulate neuronal structure and function, a favored hypothesis is that local translation of specific proteins is required for spatial and temporal regulation of changes in synaptic 
strength and dendritic morphology (Sutton and Schuman, 2006; Sanchez-Carbente and Desgroseillers, 2008). We have addressed this hypothesis by investigating the relationship between Cytoplasmic Polyadenylation Element Binding protein 1 (CPEB) containing RNP granules and dendritic branch dynamics in the developing visual system of living albino Xenopus laevis tadpoles.

CPEB is an RNA binding protein that targets mRNAs through its interaction with regulatory elements in their $3^{\prime}$ untranslated regions (Pique et al., 2008). In neurons CPEB has two distinct roles: it regulates RNP granule transport along microtubules (Huang et al., 2003), and its phosphorylation-dependent activation modulates the polyadenylation of its target mRNAs, thereby controlling their translation (Richter, 2007). Many of CPEB's neuronal target mRNAs encode known regulators of synaptic plasticity (Du and Richter, 2005; Pique et al., 2008), and our recent study has shown that interfering with CPEB protein disrupts the development of dendritic arbors and prevents neurons from integrating into the functional visual system of X. laevis (Bestman and Cline, 2008). Loss of CPEB activity in mice prevents the formation of some forms of synaptic plasticity and interferes with memory formation (Alarcon et al., 2004; Berger-Sweeney et al., 2006; McEvoy et al., 2007; Miniaci et al., 2008). These data suggest that CPEB supports the relationship between synaptic plasticity, morphological plasticity, and their regulation by dendritic protein synthesis.

RNA binding proteins are the core components of the RNP granules, and when expressed as GFP-fusion proteins, they are reliable markers of RNP granules (St Johnston, 2005). Here we have expressed cyan fluorescent protein (CFP) fusion proteins to tag both the full-length CPEB and a CPEB deletion mutant (delCPEB, $\triangle 124$ 258), lacking the activating phosphorylation site. CPEB-fluorescent protein chimeras form RNP granules and, like the endogenous protein, have been shown to transport into dendrites, associate with synapses and interact with elements of the translation apparatus (Huang et al., 2002, 2003). Because delCPEB cannot be activated by phosphorylation, its expression blocks activity-dependent increases in mRNA polyadenylation and translation (Mendez and Richter, 2001). Expressing these CPEB-CFP fusion proteins along with cytosolic yellow fluorescent protein (YFP) reveals the full dendritic arbor along with the spatial, punctate distribution of CPEB or delCPEB.

To investigate whether the distribution of CPEB-containing RNP granules affects dendritic development, we used two-photon microscopy to acquire time-lapse series that capture dendrites in the process of forming and retracting branches in the optic tectum of living $X$. laevis tadpoles. This imaging protocol allows us to identify and sort branches according to their dynamic behaviors. From our past experiments, we know that interfering with CPEB function with the expression of delCPEB severely stunted the development of the dendritic arbor over a period of days and interfered with activity-dependent dendritic development (Bestman and Cline, 2008). Serial electron microscopic analysis of tadpole tectal neurons has shown that stable dendritic branches support mature synaptic contracts, whereas dynamic dendrites form multiple immature synapses (Li et al., 2007). Given that the supply of new proteins generated from mRNA cargo of local RNP granules is thought to support changes in synaptic strength and dendritic morphology, we tested whether RNP granules would be differently distributed in or near stable branches compared to the shorter-lived dynamic branches. We further tested whether CPEB- and delCPEBcontaining RNP granules would be distributed differently in the stable versus dynamic branches of the dendritic arbor.

\section{MATERIALS AND METHODS NEURON ELECTROPORATION OF PLASMID CONSTRUCTS}

Stage 46 to 48 albino $X$. laevis tadpoles were used for all experiments. The Cold Spring Harbor Laboratory Institutional Animal Care and Use Committee approved all protocols. Plasmid constructs and neuron transfection with electroporation have been described previously (Bestman et al., 2006; Bestman and Cline, 2008).

\section{TWO-PHOTON IMAGING AND PUNCTA ANALYSIS}

One day after neurons were transfected, images were collected from anesthetized tadpoles (0.02\% MS-222; Sigma) positioned under a glass coverslip in a Sylgard chamber. Animal preparation, laser sources, signal amplification, PMT specifications, YFP/CFP filter sets, $3 \mathrm{D}$ reconstruction of neurons and punctum analyses have been described previously (Ruthazer et al., 2006). Axonal and dendritic arbors were distinguished in $3 \mathrm{D}$ reconstructions of the neurons based on the following characteristics: dendrites have larger diameters with higher density of side branches and project into the tectal neuropil with a lateral/dorsal orientation in the tectum. Axons have a uniform and smaller diameter and have few side branches. Axons form within layer 4 of the tectum, deeper than the dendritic neuropil. Using Object Image software, 3D reconstructions of the dendritic arbors were made from the raw image stacks (acquired with 1-1.5 $\mu \mathrm{m} z$ interval). Puncta positions and relative intensities of the puncta were determined along the length of digitally linearized terminal dendritic branches using automated macros. The distribution of the puncta intensities were scaled to the 80th percentile brightest punctum for each cell at each time point in order to normalize the intensity values across cells. All Object Image macros were written by Dr. E. Ruthazer, McGill University, Quebec.

\section{STATISTICAL TESTS}

Multiple comparisons were made with ANOVA and a Games/ Howell post hoc test. Differences between groups were measured with an unpaired $t$-test, differences within a group were measured with a paired $t$-test, and distributions were tested using Chi-square analysis. Six CPEB-, seven delCPEB-, and five YFP-transfected control cells were reconstructed resulting in 298,386, and 498 terminal branches, respectively, that were used for the analyses. Unless otherwise stated, data were acquired from a branch's final appearance in the time-lapse dataset. For comparisons of the distributions of punctum intensities (Figure 8), equal numbers of punctum intensity values were randomly selected and compared from branches at their last appearance in the time-lapse for each neuron group. Data presented in bar graphs are mean \pm SEM and the values are presented in Tables 1-4.

\section{RESULTS}

\section{DISTRIBUTION OF CPEB-CONTAINING RNP GRANULES}

We used two-photon microscopy to collect complete $z$-stacks of the neurons in the optic tectum of X. laevis tadpoles. CPEB-CFP and delCPEB-CFP form particles (appearing as white puncta) that 
distribute throughout the dendritic arbor (Figure 1). CPEB and delCPEB puncta are excluded from the nucleus, and the proximal dendrites of the neurons contain a high density of puncta, especially in the primary dendrite (Figure 1). CPEB and delCPEB puncta were also detected at a low density in the local axons of some tectal neurons (Figure 1). Puncta were detected in three local axons of 12 CPEB-expressing neurons examined. Puncta were associated with axon growth cones or growing branch tips (arrowhead, Figure 1A) and within the main local axon (arrow, Figure 1A). Similarly, puncta were detected in the growth cone of one axon of 12 delCPEB-expressing cells (data not shown).

Using an automated algorithm to identify the RNP puncta (Ruthazer et al., 2006), we quantified the relative positions and intensities of the CPEB-CFP and delCPEB-CFP containing RNP granules within the terminal dendritic branches. We focused on the terminal branches because they show the greatest dynamic behaviors and are the branches that contribute to building the dendritic arbor over time. We detected at least one punctum in over $90 \%$ of all terminal branches of both the CPEB and delCPEB groups (275/298 and 380/386 branches, respectively). About half of all terminal branches in CPEB- and delCPEB-expressing neurons contained more than one punctum (158/298 and 221/386 branches, respectively). The first punctum was located within $1 \mu \mathrm{m}$ of the branch point $(0.84 \pm 0.05$ and $0.78 \pm 0.04 \mu \mathrm{m}$ for full-length CPEB and delCPEB puncta, Table 1). We did not detect differences in average length of the CPEB- and delCPEB expressing terminal branches $(5.3 \pm 0.3$ and $5.6 \pm 0.3 \mu \mathrm{m}$, respectively, Table 2$)$ or in interpunctum interval, which was about $2 \mu$ for each neuron group (Table 1). For both groups, the maximum distance from the branch point to an intrabranch punctum was about $4 \mu \mathrm{m}$, about $60 \%$ of the total branch length and about $1.5 \mu \mathrm{m}$ from branch tip (Table 1). Overall, these results indicate that the distribution of CPEB- and delCPEB-RNP granules in optic tectal neurons in the intact animals are comparable, suggesting that interfering with the activitydependent actions of CPEB through the expression of delCPEB does not impact granule positions within the dynamically growing portions of the dendritic arbor.

We acquired 1-min interval time-lapse series of dendrites to see if RNP granules are mobile. Similar to reports of RNP granule mobility in cultured neurons (Knowles and Kosik, 1997; Huang et al., 2003; Antar et al., 2004, 2005; Dynes and Steward, 2007), our results revealed that the $\mathrm{CPEB}$ and delCPEB puncta largely exhibited oscillatory movements, with no net change in position over time (Figures 2-4 and Supplementary Videos 1-3). The high density of puncta in the branches combined with their oscillatory movements often resulted in image sequences where two or more puncta appear to fuse together and split apart, precluding their unambiguous identification through the time series even with the 1-min interval time points (Figure 2, inserts and Figure 3). Despite this, obvious directional movements of some puncta could be resolved across time points over the series (arrows, Figure 2). The mobility of the CPEBand delCPEB-containing RNP granules was not detectably different from one another. In the relatively shorter terminal branches puncta did not display clear directional movements (Figures 2-4), but new puncta appear and coalesce and change intensity over time (Figures 3-4 and Supplementary Videos 2 and 3). These data suggest that the majority of RNP granules imaged in neurons in the intact animal undergo relatively small local movements and that a minority exhibit directional movements.

\section{IMPACT OF CPEB AND deICPEB EXPRESSION ON DYNAMIC BRANCH BEHAVIOR}

Our past work showed that interfering with $\mathrm{CPEB}$ function in optic tectal neurons over periods of days disrupts dendritic arbor development and circuit function and blocks experience-dependent structural plasticity (Bestman and Cline, 2008), but the potential role of CPEB function in regulating dynamic branching on a timescale of minutes to hours had not been explored. We used twophoton microscopy to collect 10-min interval, time-lapse images of the dendritic arbor over $1 \mathrm{~h}$. This imaging protocol captures

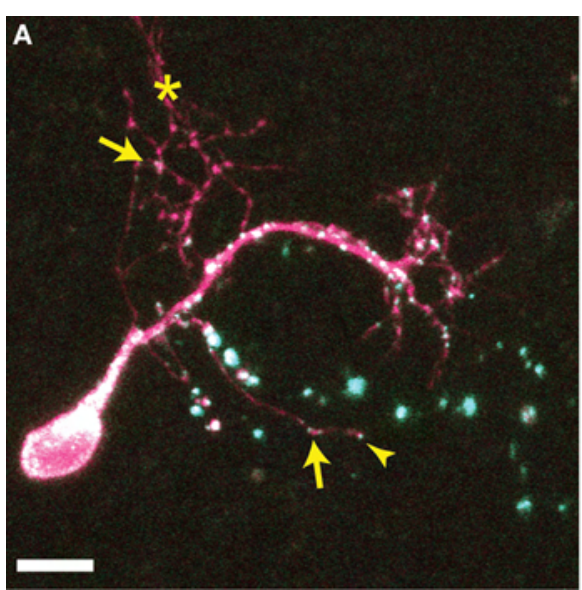

FIGURE 1 | Distribution of CPEB- and deICPEB-containing RNP granules in optic tectal neurons. Optic tectal neurons labeled with cytosolic YFP (magenta) and CPEB-CFP (A) or delCPEB-CFP (B). CFP-tagged RNP granules are green puncta that when overlapping with magenta, appear white. Labeled RNP granules

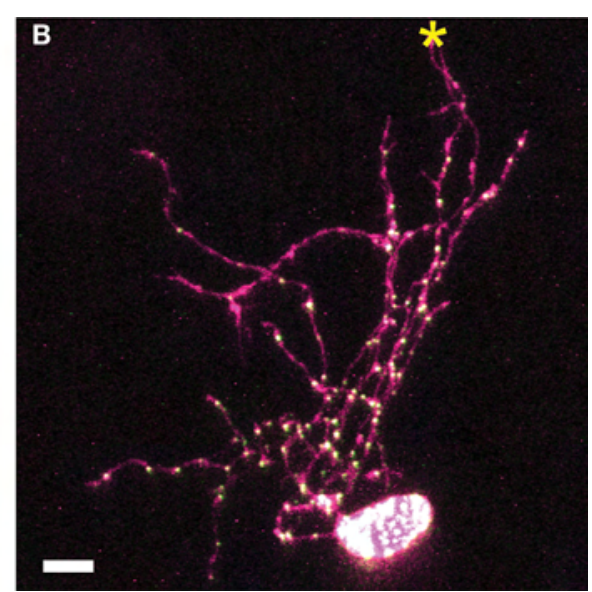

are distributed throughout the dendritic arbor of all cells imaged, whereas axons in $25 \%$ of the cells contain RNP granules. Examples of puncta in the locally branching axon (axons indicated with asterisks): arrows point to puncta within the axon arbor and arrowhead points to punctum at an axon tip. Scale bars $=10 \mu \mathrm{m}$ 
Table 1 | Puncta positions within the terminal branches.

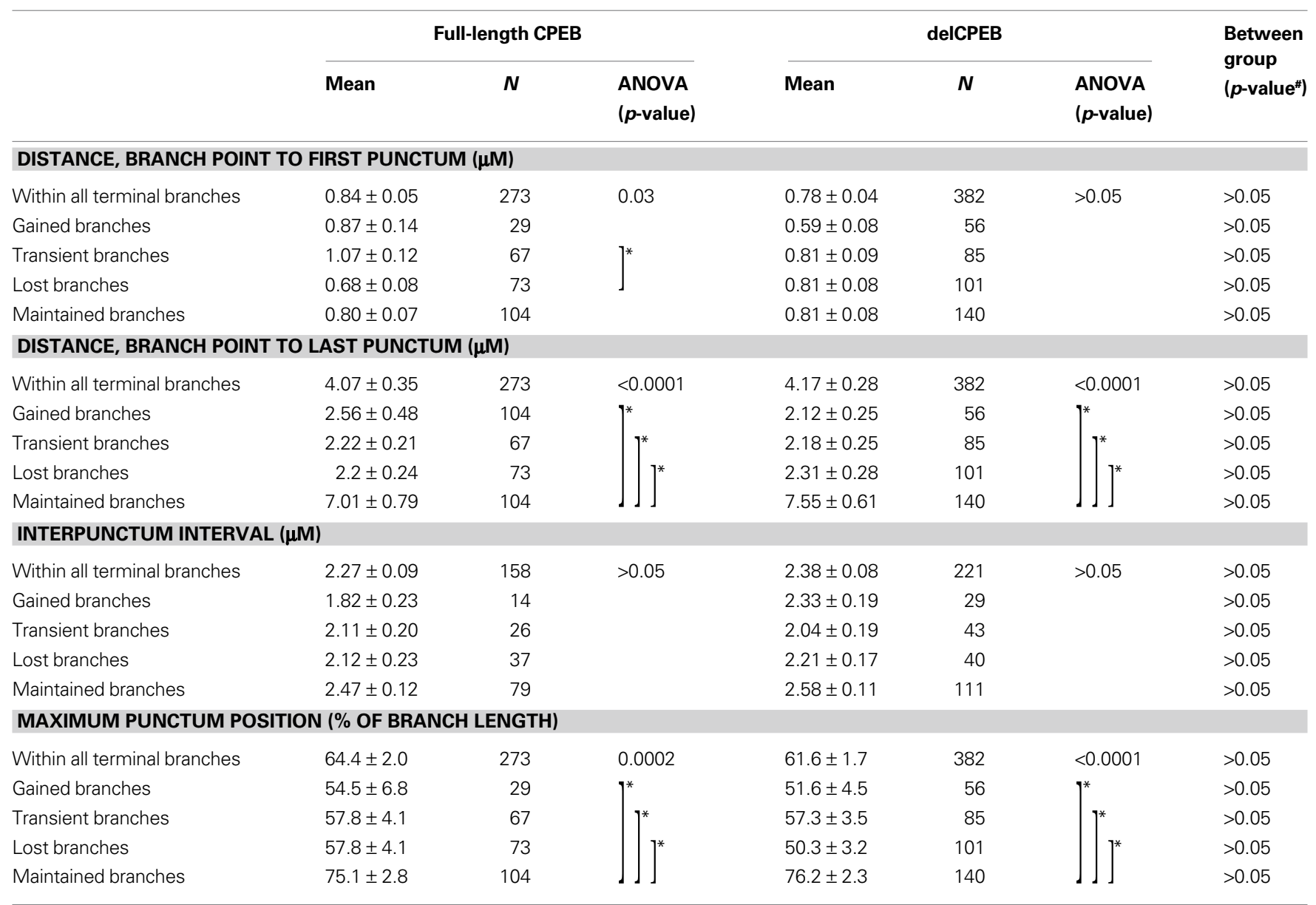

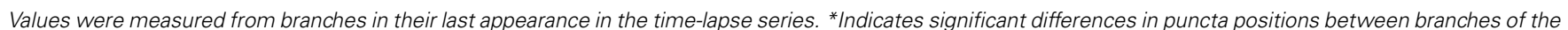
same cell group. ANOVA with Games/Howell post hoc test. "Differences between CPEB and delCPEB groups measured with unpaired t-test.

fine-scale branch dynamics, but not large-scale changes in the dendritic arbor (Cline, 2001).

We reconstructed the dendritic arbor of neurons expressing only YFP, or YFP with full-length CPEB and delCPEB to create full 3D representations of the dendritic architecture for each of the seven time points (Figure 5). Individual terminal branches, the branches with the greatest dynamic behaviors, were identified and followed over the 60-min experiment to quantify the changes in their branch lengths, and to categorize them according to their dynamic properties as follows (Figure 5D): maintained branches appeared in all of the time points (black), gained branches were absent at the first time point and present in the last time point (green); transient branches were both added and completely retracted within the imaging session (pink); and lost branches were present in the first time point and disappeared by the last time point (blue; color coded in Figures 5A-C).

The average branch lengths and dynamic branch behaviors between the terminal branches of control YFP-, CPEB-, and delCPEB-expressing neurons were comparable (Figure 6 and Table 2; unpaired $t$-test and Chi-square $p>0.05$ ). Across the three groups of neuron, approximately equal proportions of the branches were maintained for the duration of the 60-min experiment.
Of the dynamic branches, about $40 \%$ were lost, $40 \%$ appeared transiently and about $20 \%$ were added over the course of the 60 min (Figure 6A and Table 2). The proportion of branches that increased, decreased or experienced no change in branch length over the 60-min experiment was also not different between the neuron groups (Figure 6B and Table 2). However, cells expressing delCPEB had fewer branches that appeared for just one time point (Chi-square $p=0.01$; Figure $6 \mathrm{C}$ ), and the relative duration of delCPEB-expressing gained and lost terminal branches was $\sim 1.5$ times longer than that of control branches (Table 2 and Figure 6D). These data suggest that delCPEB expression shifts branch dynamics so that when branches are present, they persist longer and are more resistant to retraction.

\section{BRANCH DYNAMICS DO NOT CORRELATE WITH PUNCTUM POSITIONS}

CPEB-containing RNP granules, like other RNP granules, are sites where mRNAs are quiescently held and are thought to serve as sources of mRNA for local translation following synaptic activity. This suggests that the distribution of CPEB-containing RNP granules may correlate with sites of branch dynamics or growth. One hypothesis is that CPEB granule distribution may differ between stable branches and dynamic branches. Another hypothesis is that 

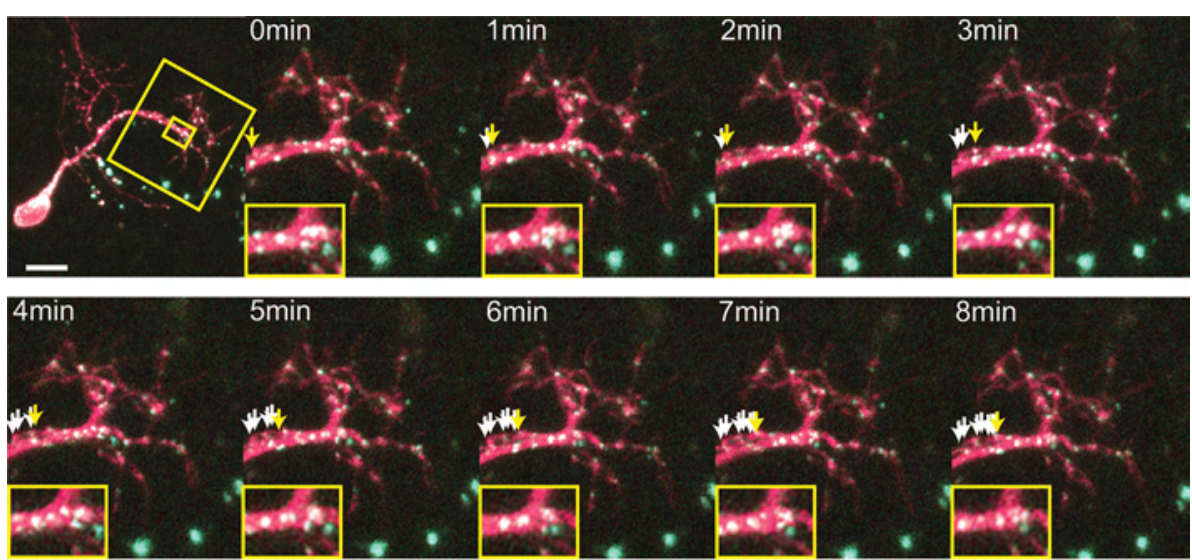

$6 \mathrm{~min}$

$7 \mathrm{~min}$

$8 \mathrm{~min}$

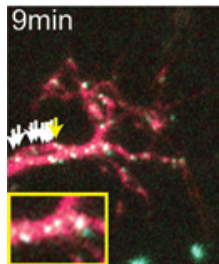

$10 \mathrm{~min}$
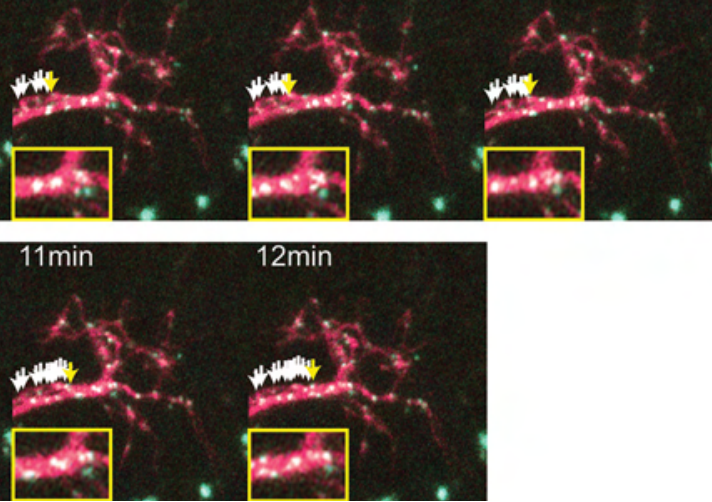

FIGURE 2 |Time-lapse of CPEB-CFP/YFP expressing tectal neuron. One minute interval time-lapse frames made of the dendrites of the CPEB-CFP/YFP-expressing cell in Figure 1A. The time-lapse series focuses on the boxed area of the dendrites. Arrows indicate the progressive history of locations of one punctum over the 12 min, with the current position in yellow, past positions in white. Smaller insert illustrates the rapid fusing and splitting of puncta. Scale bar $=10 \mu \mathrm{m}$. See also Supplementary Video 1.
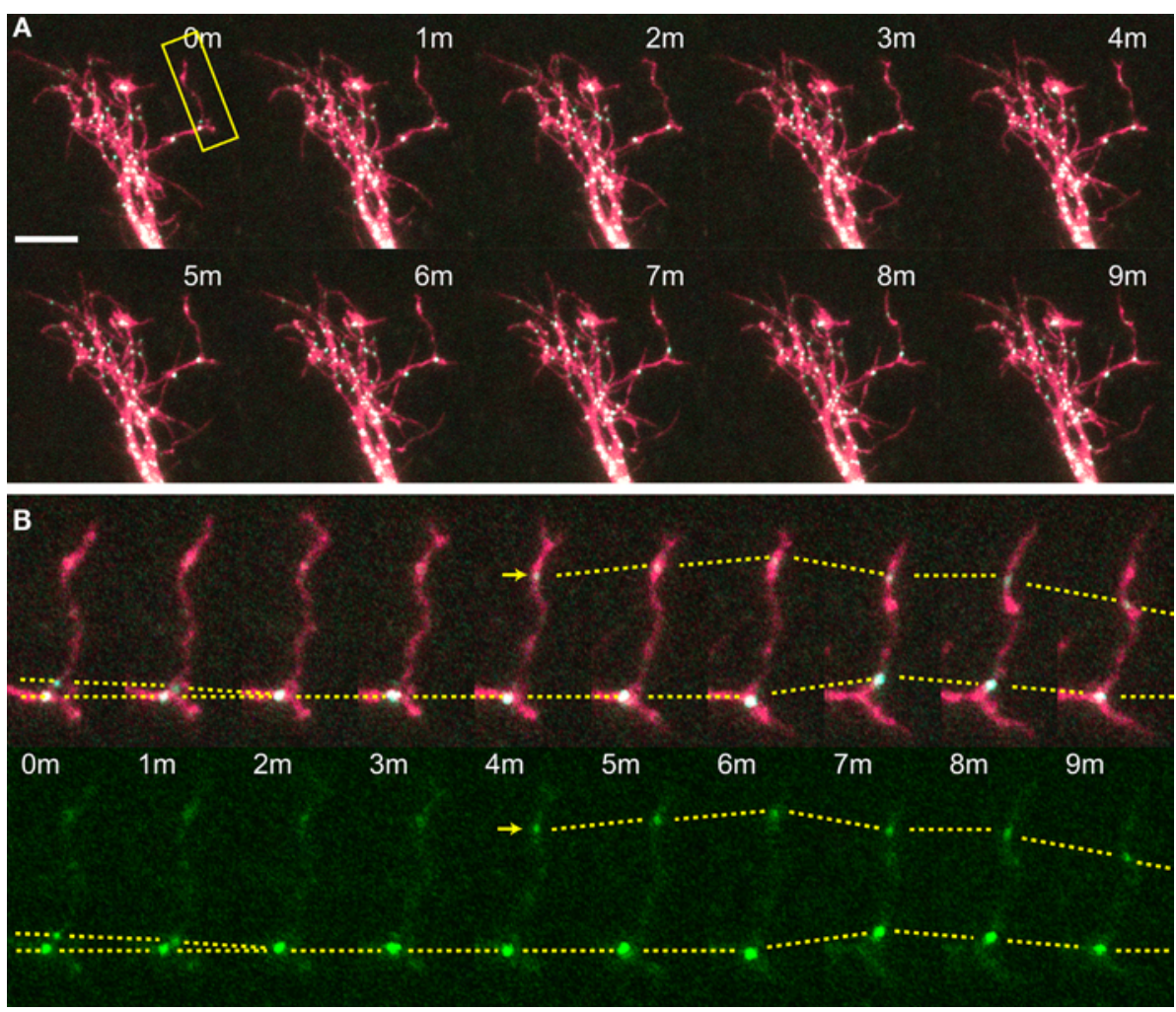

FIGURE 3 |Time-lapse of CPEB-CFP/YFP-expressing tectal neuron. One minute interval time-lapse frames made of the dendrites of a CPEB-CFP/ YFP-expressing optic tectal neuron (A), with the dendritic branch boxed in yellow shown in (B). Arrow indicates the formation of a punctum and dotted lines follow puncta between time points and indicate puncta that fuse together and shift position. Scale bar $=10 \mu \mathrm{m}$. See also Supplementary Video 2 . 

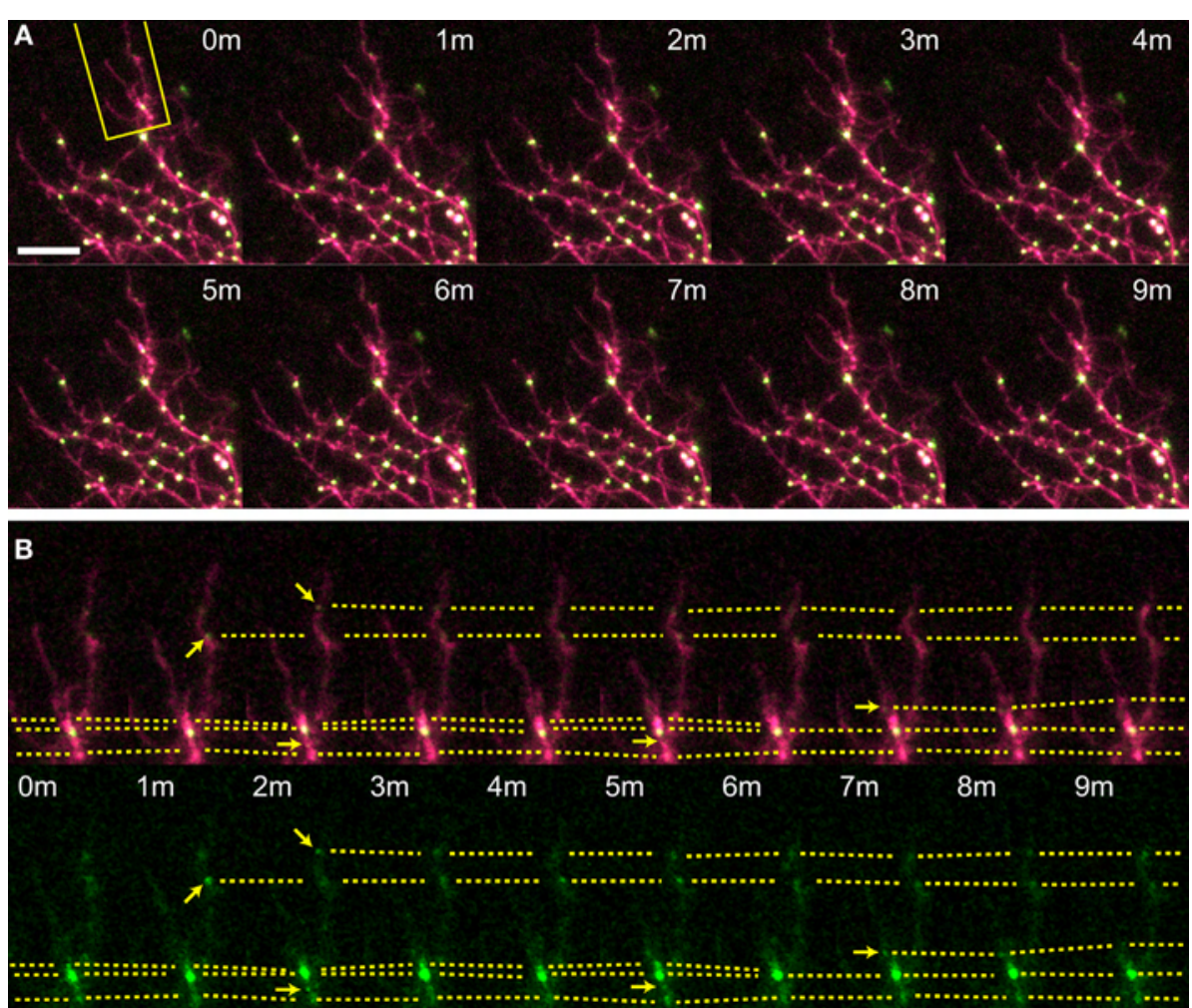

FIGURE 4 |Time-lapse of deICPEB-CFP/YFP expressing tectal neuron. One minute interval time-lapse frames made of the dendrites of a delCPEB-CFP/ YFP-expressing optic tectal neuron (A), with the dendritic branch boxed in yellow shown in (B). Arrows indicate the formation of a punctum and dotted lines follow puncta between time points and indicate puncta that fuse together and shift position. Scale bar $=10 \mu \mathrm{m}$. See also Supplementary Video 3 . granules may selectively move into extending or retracting branches. A third hypothesis is that granules with different RNP composition may correlate with branch dynamics. Sorting the branches by their dynamic behaviors revealed that puncta extended about $20 \%$ deeper (Table 1) into the maintained branches of both CPEBand delCPEB-expressing neurons than the three classes of dynamic branches (gained, lost, and transient). Other features of puncta distribution, for example, the distance from the branch point to the first punctum or the interpunctum interval, were not different between the maintained and dynamic branches (Table 1).

The neuron shown in Figure 7 illustrates how the positions of CPEB-labeled RNP granules do not predict branch dynamics over time. 3D reconstructions were made of the dendritic arbor of a CPEB-CFP/YFP-expressing neuron imaged every $10 \mathrm{~min}$ for $1 \mathrm{~h}$. In the projection of the $3 \mathrm{D}$ reconstruction, two main branches (depicted in green in Figures 7C,D,F,G) and their side branches (depicted in pink in Figures 7C,D,F,G) were selected to spotlight a branch and side branches with little dynamic behavior (Figures 7C,D), and another with dynamic branch additions and retractions (Figures 7F,G). These branches were digitally linearized and the positions and relative intensities of the CPEB-CFP puncta are shown along with arrows indicating the branch points of the smaller side branches (Figures 7E,H). These examples show that, as we describe in Section "Distribution of CPEB-containing RNP Granules," terminal branches are highly likely to have a punctum near their branch points, but that the presence of a punc- tum does not correlate with either the loss of a branch (branch 5 in Figure $7 \mathbf{H}$ ) or appearance of a new branch (branches 11-13, Figure $7 \mathbf{H})$.

\section{deICPEB ACCUMULATES IN RNPS}

While the overall spatial positions of the puncta in the terminal branches of the CPEB and delCPEB neuron groups did not show detectable differences, we did find that the range of punctum intensities in terminal branches of delCPEB-expressing neurons is shifted toward higher values than those in neurons expressing fulllength CPEB (Figure 8A; Kolmogorov-Smirnov test, $p<0.0001$ ) and the mean intensity of the delCPEB puncta within the terminal branches was significantly greater than that of the full-length CPEB puncta (Figure 8A, insert, and Table 3). The punctum nearest the branch point shows the greatest difference in intensity values; the mean intensity of these delCPEB puncta was about 1.5 times greater than that of CPEB-expressing cells $(p=0.002$; Figures 8B,C and Table 3 ). The intensity of the puncta nearest the branch point of the lost and maintained branches showed the greatest differences between the delCPEB and CPEB groups $(p=0.01$ and 0.05 , respectively, Figure 8B). While the intensity of the puncta nearest the branch points did not differ between the different classes of dynamic branches of the CPEB-expressing cells, this was not the case for the delCPEB-expressing cells; the intensity of the puncta nearest the branch point of the lost and maintained branches was significantly greater than that of 

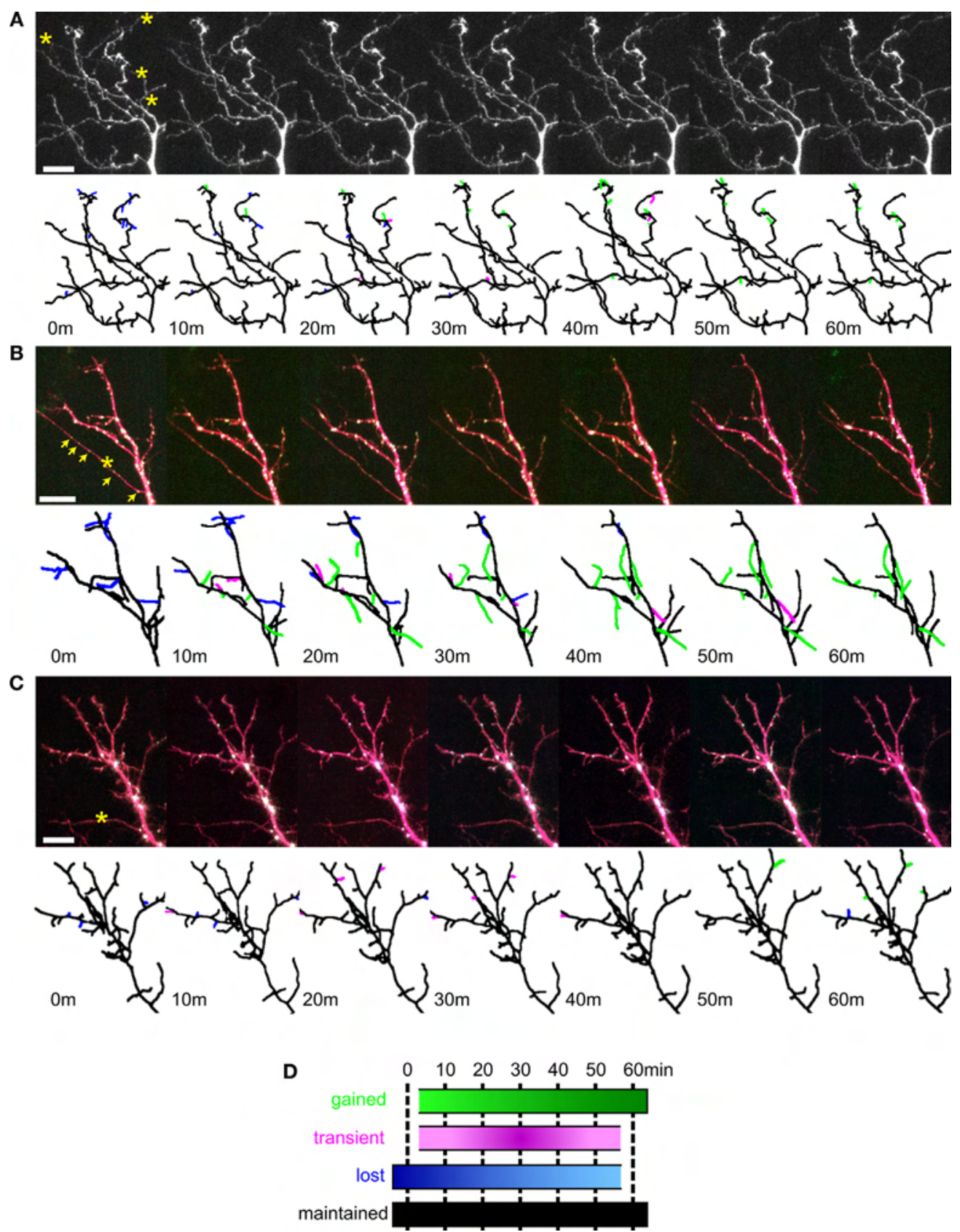

FIGURE 5 | Dynamic branch behaviors of tectal neurons expressing YFP, CPEB, and deICPEB. Example of dendrites from a control cell expressing YFP alone (A), full-length CPEB-CFP and YFP (B) and delCPEB-CFP and YFP (C) Each cell was imaged seven times, once every $10 \mathrm{~min}$. Below each photomicrograph is the projection of the 3D reconstruction of the dendritic arbor with the branches color coded to reflect their behaviors (illustrated in $\mathbf{D}$ over the course of the $60 \mathrm{~min}$. (B,C) CFP-labeled RNP granules appear as white puncta when colocalized with the YFP (in magenta). (D) Diagram illustrating the four categories of branch behaviors. Maintained branches appeared in all of the time points. The remaining branches fall into three groups: gained, branches that were absent initially and present in the last time point; transient, branches that were both added and completely retracted within the imaging session; and lost, branches that were present in the first time point and absent by the last time point. Axons are marked with asterisks, and arrows indicate puncta that are within the axon. Scale bars $=10 \mu \mathrm{m}$. See also Supplementary Videos $4 \mathrm{~A}-\mathrm{C}$. the transient branches ( $p=0.04$; Figure $8 \mathrm{~B}$ and Table 3$)$. The puncta intensities are not significantly different between the two groups of neurons initially, and did not increase in CPEBexpressing neurons over the course of the time-lapse experiment. In contrast, the intensity levels of the punctum nearest the branch point (Figure 8C and Table 4) or the sum of all the puncta within a delCPEB-expressing terminal branch (Figure 8D and Table 4) increased significantly from the time of the branch's first appearance compared to its last appearance (Figures 8C,D and Table 4). 

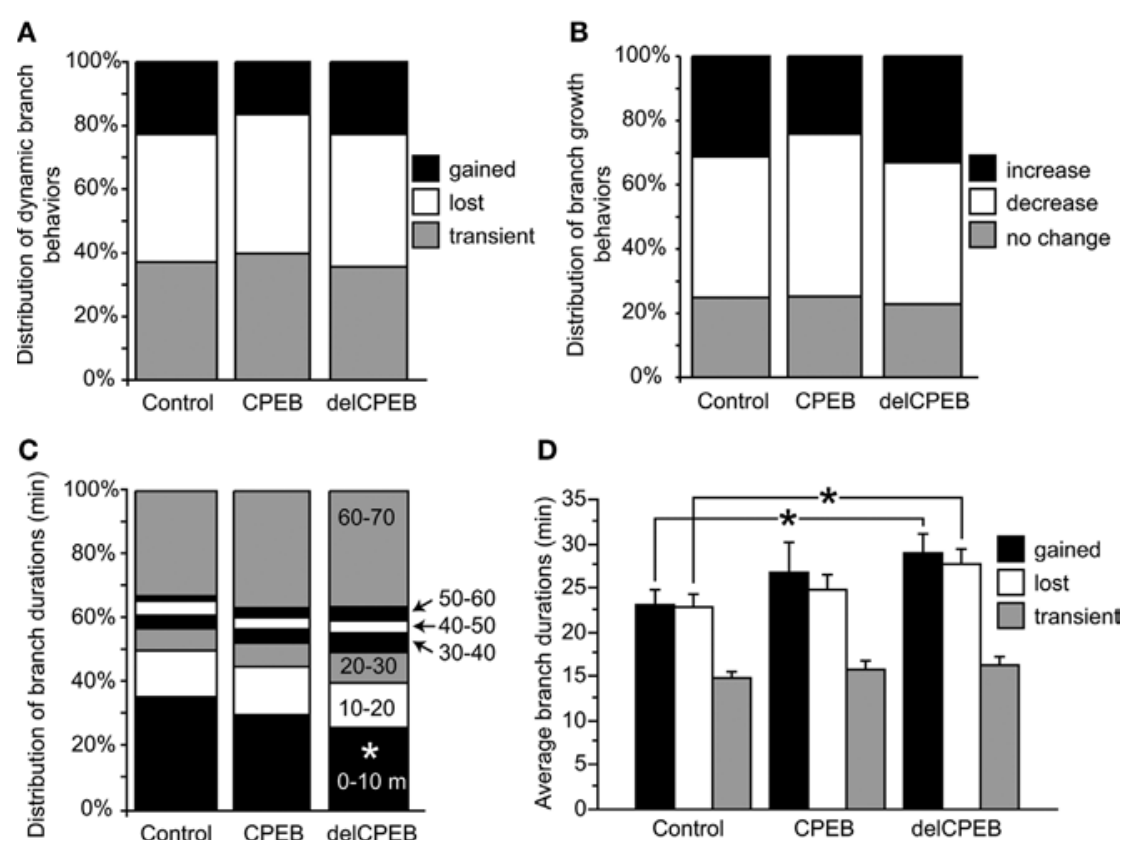

FIGURE 6 | Quantification of branching behaviors. (A,B) ControlYFP-, full-length CPEB-, or delCPEB-expressing cells have similar proportions of branches with different dynamic branch behaviors (A) and with similar increases or decreases in branch length over the course of the 60-min experiment (B). (C) Proportion of branches with different durations in control, CPEB-and delCPEB-expressing neurons. delCPEB-expressing cells have fewer branches that were present for a single time point of the experiment compared to control cells (Chi-square, $p=0.01$ ). (D) Durations of the dynamic branches of the controlYFP-, CPEB-, and delCPEB-expressing neurons. The gained and lost branches of delCPEB-expressing neurons were present for significantly longer periods than control cells (unpaired $t$-test, $p=0.02$ and 0.03 , respectively). Values were measured from branches in their last appearance in the time-lapse. See Tables $\mathbf{1}$ and $\mathbf{2}$ for values.

\section{DISCUSSION}

In neurons, CPEB has two distinct roles: it regulates RNP granule transport in the dendrites by forming a link between the granules and motor proteins, and it directs the polyadenylation and translational de-repression of its target mRNAs in response to glutamatergic synaptic activity. Developing neurons in the optic tectum can increase the size of their dendritic arbor by orders of magnitude over a period of a few days, and when CPEB activity is disrupted by the overexpression of the delCPEB deletion mutant, the normal processes of branch addition and retraction are prevented, resulting in a severely dwarfed dendritic arbor (Bestman and Cline, 2008). Here our focus has been on dynamic branching events seen with short-interval imaging protocols, and their potential relationship to CPEB- and delCPEB-containing RNP granules. Our results suggest that the granules are ubiquitously distributed throughout the arbor, regardless of the eventual fate of the branches with which they associate or whether the RNP granules contained the active full-length $\mathrm{CPEB}$ or the inactive delCPEB protein. Comparing the branches containing CPEBand delCPEB-labeled puncta revealed that over the 60 -min time course of the experiment, neurons expressing the activity-insensitive delCPEB protein accumulate protein in their puncta. Taken together, our results suggest that branch dynamics relating to structural plasticity are not regulated through the directed movement of the CPEB-containing RNP granules to specific sites in the dendritic arbor, but that the regulation of the CPEB content in granules correlates with branch dynamics. Our data are consistent with a model in which mRNA and mRNA binding proteins disperse from RNP granules and contribute to changes in local protein levels.

\section{CPEB ACTIVITY ALTERS DENDRITIC BRANCH DYNAMICS, BUT NOT PUNCTA DISTRIBUTION}

The branching activity of the terminal dendritic branches of neurons expressing delCPEB was reduced over the 60-min time-lapse period, compared to the YFP-expressing control neurons. The delCPEB-expressing tectal neurons tended to have more, longer lived branches (Figures 6C,D). Neurons expressing full-length CPEB were comparable to the YFP control cells in their growth patterns. As neurons choose partners and integrate into neural circuits, they build their dendritic arbor through a trial and error process of branch addition and retraction. Our data suggests that $\mathrm{CPEB}$ plays a role in this process because branching dynamics are slower than controls in the delCPEB-expressing neurons, where normal CPEB activity is disrupted. It is likely that over time this would put these cells at a disadvantage during circuit development. Indeed, we have seen that this delCPEB expression prevents neurons from elaborating a dendritic arbor and integrating into the visual circuitry (Bestman and Cline, 2008).

Both full-length CPEB and delCPEB form granules that distribute in the dendritic arbor of cultured neurons (Huang et al., 2003), but the distribution of full-length CPEB and delCPEB puncta had not previously been compared quantitatively. mRNAs are translationally repressed in granules and RNP granule contents 


\begin{tabular}{|c|c|c|c|c|c|c|}
\hline & \multicolumn{2}{|c|}{ Control } & \multicolumn{2}{|c|}{ Full-length CPEB } & \multicolumn{2}{|c|}{ delCPEB } \\
\hline & Mean & $N$ & Mean & $N$ & Mean & $N$ \\
\hline All branches & $5.7 \pm 0.3$ & 498 & $5.3 \pm 0.3$ & 298 & $5.6 \pm 0.3$ & 386 \\
\hline Transient branches & $3.3 \pm 0.2$ & 124 & $3.6 \pm 0.3$ & 75 & $3.5 \pm 0.2$ & 88 \\
\hline Lost branches & $3.6 \pm 0.2$ & 134 & $3.6 \pm 0.3$ & 83 & $4.1 \pm 0.3$ & 102 \\
\hline Gained branches & $3.8 \pm 0.2$ & 76 & $4.2 \pm 0.5$ & 31 & $4.2 \pm 0.3$ & 56 \\
\hline \multicolumn{7}{|l|}{ AVERAGE BRANCH DURATION (MIN) } \\
\hline Gained branches & $23.0 \pm 1.6$ & 76 & $26.8 \pm 3.3$ & 31 & $28.9 \pm 2.2^{* *}$ & 56 \\
\hline Lost branches & $22.8 \pm 1.4$ & 134 & $24.8 \pm 1.7$ & 82 & $27.7 \pm 1.6^{*}$ & 103 \\
\hline Transient branches & $14.8 \pm 0.8$ & 124 & $15.7 \pm 1.2$ & 75 & $16.25 \pm 1.1$ & 88 \\
\hline Maintained branches & 32.9 & 164 & 36.6 & 109 & 36.3 & 140 \\
\hline Lost branches & 26.9 & 134 & 27.9 & 83 & 26.4 & 102 \\
\hline Transient branches & 24.9 & 124 & 25.2 & 75 & 22.8 & 88 \\
\hline Gained branches & 15.3 & 76 & 10.4 & 31 & 14.5 & 56 \\
\hline DISTRIBUTION OF BRANCH GROWTH BEHAVIORS & 100 & 498 & 100 & 298 & 100 & 386 \\
\hline No change in branch length & 43.8 & 124 & 25.2 & 75 & 22.8 & 88 \\
\hline Decrease in branch length & 31.3 & 218 & 50.7 & 151 & 44.0 & 170 \\
\hline Increase in branch length & 24.9 & 156 & 24.2 & 72 & 33.2 & 128 \\
\hline DISTRIBUTION OF BRANCH DURATIONS & 100 & 498 & 100 & 298 & 100 & 386 \\
\hline \multicolumn{7}{|l|}{ Time point (minute) } \\
\hline
\end{tabular}

Values of terminal branch lengths were measured from branches in their last appearance in the time-lapse series. Unpaired t-test, ${ }^{*} p=0.02$ and ${ }^{*} p=0.03$.

are thought to be released from granules to initiate translation. RNP granules could accumulate when signals for local translation decrease or local signals could promote directed trafficking to active sites in the arbor. Ours is the first study to make measurements of the dendritic distribution of any RNP granule neurons in a living animal. Because the phosphorylation site removed in the del$\mathrm{CPEB}$ deletion is required for activating the protein downstream of synaptic input, and subsequent initiation of protein synthesis, we hypothesized that the delCPEB-labeled puncta might be localized differently compared to the full-length CPEB-labeled puncta. We did not, however, detect any differences in the distribution of the full-length CPEB or the delCPEB in the terminal branches. The neuron groups were comparable in puncta numbers, interpunctum distances and puncta positions within the terminal branches. These data suggest that the distribution of CPEB-containing RNP granules in the dendritic arbor is not affected by the activation of the CPEB protein.

\section{DYNAMIC BRANCH BEHAVIOR DOES NOT IMPACT THE DISTRIBUTION OF RNP GRANULES}

The previous representations of dendritic RNP granule distribution from cultured hippocampal and cortical neurons are very similar to what we have found with tectal neurons in vivo. RNP granules have been labeled with a variety of methods, for example with vital dyes like SYTO-14 (Knowles et al., 1996), or by tagging the RNP granule proteins (Zhang et al., 2001; Huang et al., 2003; Antar et al., 2004) and mRNA transcripts (Rook et al., 2000; Dictenberg et al., 2008). Like our results, these labeling methods revealed that the granules are widely distributed throughout the dendritic arbor. As has been noted in past work with cultured neurons (Rook et al., 2000; Zhang et al., 2001; Ferrari et al., 2007; Dictenberg et al., 2008), we detected a high number of RNP granules at the branch points of the tectal neurons. CPEBand delCPEB-labeled RNP granules at the branch points also tended to have greater fluorescence intensity than labeled puncta 

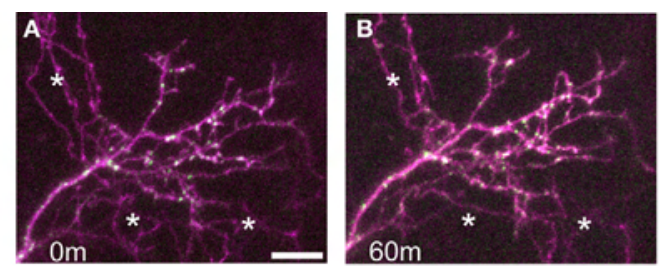
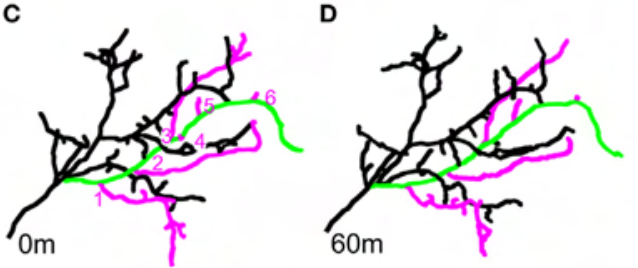

E

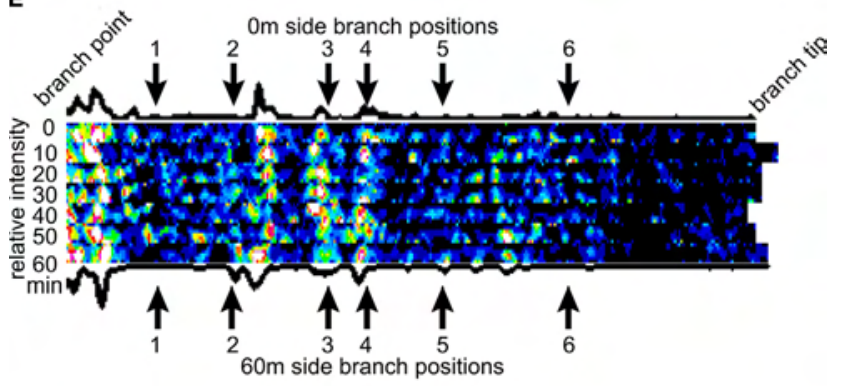

F


FIGURE 7 | Dendritic branching is not predicted from RNP puncta positions. (A,B) Example of a tectal neuron expressing CPEB-CFP/YFP imaged once every 10 min over $1 \mathrm{~h}$ at the 0 -min (A) and 60-min (B) time point. (C,D) Projection of the 3D reconstruction made from the $0-\mathrm{min}$ (C) and 60-min (D) time point. The six side branches (in pink) that appear on the green branch are stable for the duration of the 60-min experiment. (E) The green branch from (C) and (D) was digitally linearized for each of the seven time points, and the CFP fluorescence along the branch is shown with the branch positioned with the branch tip to the right. The arrows indicate the branch point sites of the six side branches. (F,G) The green branch in this representation of the 0 -min time point (F) and 60-min time point $(\mathbf{G})$ loses its 5 th side branch and gains three side branches (11, 12, and 13) over the $1 \mathrm{~h}$ time-lapse period. $(\mathbf{H})$ The CFP content of the green branch from $(\mathbf{F})$ and $(\mathbf{G})$ as described in (E). Scale bar $=10 \mu \mathrm{m}$. located more distally in the terminal branches. Whether these RNP granules located at branch points represent a distinct class of granules or aggregations of RNP granules as they are being sorted and transported into the dendritic arbor is not clear. Nonetheless it is noteworthy that cellular specializations like synapses (Niell et al., 2004), and organelles like Golgi outposts (Horton et al., 2005) and ribosomes (Tiedge and Brosius, 1996) have also been shown to occur at dendritic branch points. The proximity of RNP granules and these cellular components with synapses suggests that input-specific signaling could coordinate protein synthesis and post-translational processing to provide local control of cytosolic or transmembrane proteins required for synaptic plasticity.

RNA binding proteins interact with motor proteins to propel RNP granules along the microtubules in the dendritic arbor (Hirokawa, 2006). There is ample evidence that application of $\mathrm{KCl}$, neurotransmitters or trophic factors can stimulate the trafficking of RNP granules in cultured neurons (Kiebler and Bassell, 2006). From these data it has been suggested that synaptic input may regulate RNA granule motility in the dendrites or that RNP granules may be directed to activated areas of the dendritic arbor that require new protein synthesis (Steward and Schuman, 2003; Kiebler and Bassell, 2006; Dahm et al., 2007; Sanchez-Carbente and Desgroseillers, 2008), however, it remains uncertain whether the stimulation-induced transport of RNP granules reflects a simple increase in granule motility or true oriented movement of RNP granules to activated areas of the dendrite (Cougot et al., 2008). It is difficult to compare the level or type of input the neurons in our study receive from their contacts within the tectum with the input levels of globally stimulated cultured neurons, but our results do not support a model of directed RNP granule movement within the dendritic arbor. We used the time-lapse data to identify branches by their dynamic behaviors or their growth histories and tested whether the branch's history correlated with the distribution of CPEB- or delCPEB-containing granules. Because we found no evidence for a correlation between the distribution of CPEB- or delCPEB-containing granules and branch dynamics, our data suggest that the regulation of granule distribution is not a controlling factor in structural plasticity in vivo. The high density of RNP granules, relative to the density of side branches emerging from a dendrite, suggests that the presence of CPEB-containing granules may not be limiting for structural plasticity.

\section{LOCAL CONTROL OF DENDRITIC PROTEIN SYNTHESIS RESIDES IN TRANSLATION CONTROL}

While there were no detectable differences in puncta numbers or spatial distributions between delCPEB-expressing and CPEBexpressing neurons, we found that within terminal branches the average fluorescence intensity levels of all puncta, the sum of intensities of all puncta per branch, or the intensity of only the punctum nearest the branch point of the delCPEB-expressing neurons were higher than those of the translationally active CPEB-expressing neurons (Figure 8). In addition, the relative fluorescence intensity of puncta within the terminal branches of delCPEB-expressing neurons significantly increased over the course of the time-lapse, but the intensities of the RNP granules 
A

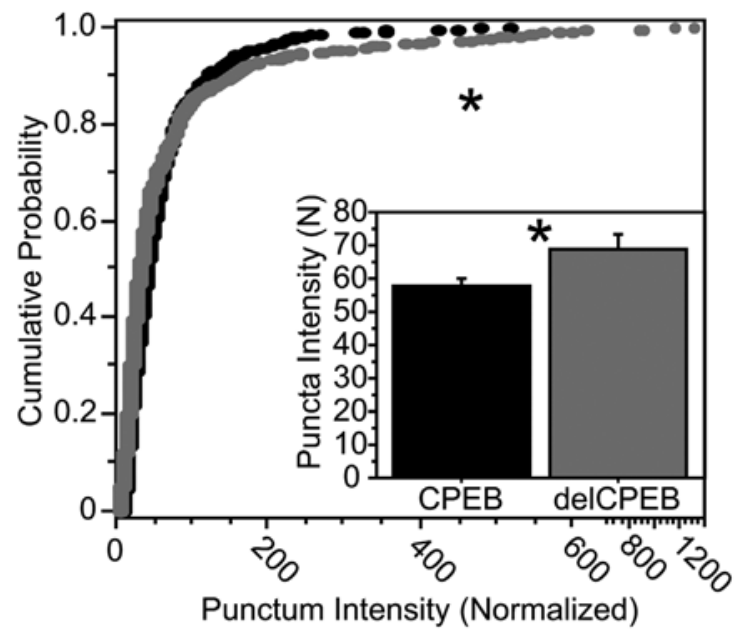

C

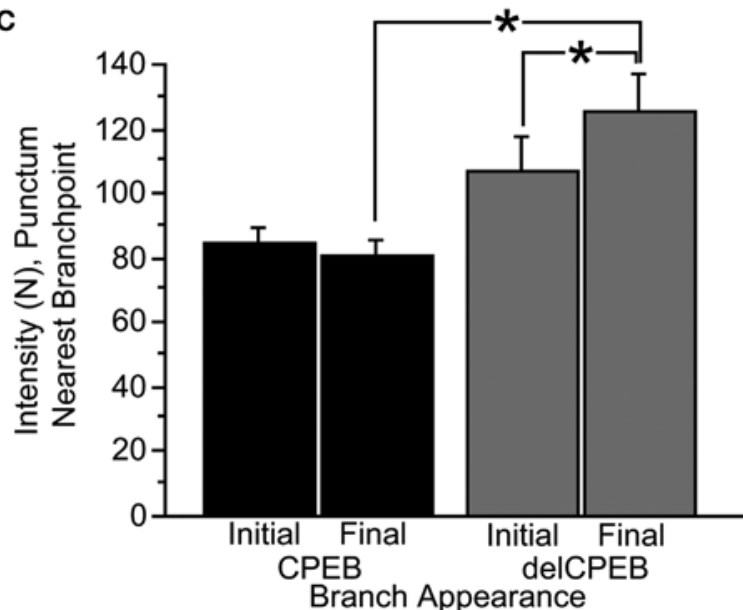

FIGURE 8 | delCPEB puncta have greater fluorescence intensity values than CPEB puncta. (A) The distributions of intensities of the puncta from delCPEBexpressing neurons, or the mean puncta intensity (inset) are significantly higher than those of the CPEB-expressing cells (Kolmogorov-Smirnov test, $p<0.0001$ and unpaired $t$-test, $p=0.04$ ). (B) Together, the delCPEB-expressing cells have a higher fluorescence intensity of the puncta nearest the branch points than CPEB-expressing cells (unpaired $t$-test, $p=0.002$ ). The lost and maintained delCPEB-expressing neuronal branches have higher branch point puncta
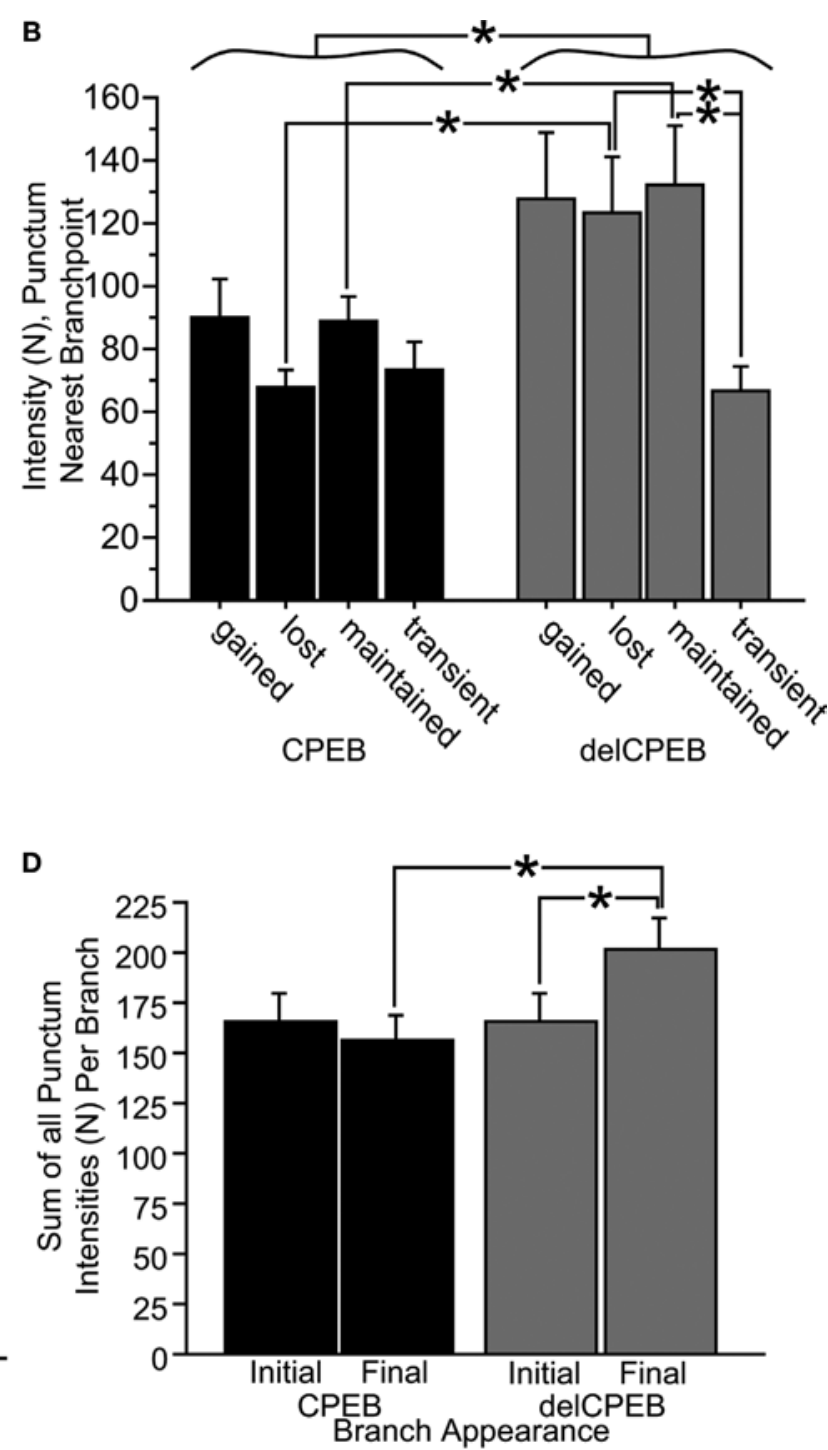

intensity levels compared to transient branches or the branch point puncta intensity values for lost and maintained branches of the CPEB-expressing neurons. (C,D) The mean intensity values of the branch point puncta (C) or a sum of all the puncta within a branch (D) show that compared to CPEBexpressing neurons, delCPEB-expressing cells have a significant increase in punctum intensities over the branches duration in the time-lapse, reaching values that are significantly greater than cells expressing CPEB. See Tables $\mathbf{3}$ and $\mathbf{4}$ for values. of the CPEB-expressing neurons did not change over the same period (Figure 8).

Although it is often reported that dendritically-localized RNP granules localize to branch points in the dendritic arbor (Rook et al., 2000; Zhang et al., 2001; Ferrari et al., 2007; Dictenberg et al., 2008), it is not clear why RNP granules at branch point locations would have higher $\mathrm{CPEB}$ content compared to the granules found more distally in the branches. It is possible that the intensity differences of the granules localized at branch points are indicative of different functional groups of CPEB-labeled granules. Neurons contain multiple classes of RNA granules (Kiebler and Bassell, 2006). In addition to its presence in transport RNP granules in neurons (Huang et al., 2003), like many other RNA binding proteins CPEB has also been shown to associate with RNA processing bodies and stress granules (Wilczynska et al., 2005). Little is known about the relative distribution of different granule types in neurons, the relationship between the different granule classes, and how each granule type may interact to process mRNAs or together contribute to the trafficking and translational regulation of mRNAs (Kiebler and Bassell, 2006). 
Table 3 | Punctum intensity in the different terminal branches.

\begin{tabular}{|c|c|c|c|c|c|c|c|}
\hline \multirow[t]{2}{*}{ Average punctum intensity } & \multicolumn{3}{|c|}{ Full-length CPEB } & \multicolumn{3}{|c|}{ delCPEB } & \multirow{2}{*}{$\begin{array}{l}\text { Between } \\
\text { group } \\
(p \text {-value })^{\#}\end{array}$} \\
\hline & Mean & $N$ & $\begin{array}{l}\text { ANOVA } \\
\text { (p-value) }\end{array}$ & Mean & $N$ & $\begin{array}{l}\text { ANOVA } \\
\text { (p-value) }\end{array}$ & \\
\hline All puncta & $57.7 \pm 2.4$ & 657 & - & $68.8 \pm 4.8$ & 657 & - & 0.04 \\
\hline \multicolumn{8}{|l|}{ Punctum nearest branch point of: } \\
\hline All branches & $79.1 \pm 4.4$ & 273 & $>0.05$ & $114.6 \pm 9.5$ & 381 & 0.04 & 0.002 \\
\hline Only lost branches & $67.2 \pm 6.6$ & 73 & & $123.3 \pm 17.6$ & 101 & $l^{*}$ & 0.01 \\
\hline Only maintained branches & $88.4 \pm 7.8$ & 104 & & $132.6 \pm 18.5$ & 140 & ]$^{*}$ & 0.05 \\
\hline Only transient branches & $72.8 \pm 9.5$ & 67 & & $66.6 \pm 8.4$ & 85 & ] & $<0.05$ \\
\hline
\end{tabular}

Values were measured from branches in their last appearance in the time-lapse. *Indicates significant differences in puncta intensity between branches of the

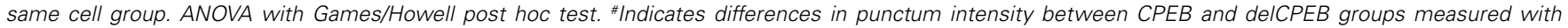
unpaired t-test.

Table 4 | Changes in punctum intensity.

Full-length CPEB

\begin{tabular}{ll}
\hline Branch appearance & $p$-value*
\end{tabular}

\section{AVERAGE INTENSITY}

Sum of all puncta per branch

First punctum (nearest branch point)
Final

$166.3 \pm 14.1 \quad 155.9 \pm 12.6>0.05$

$84.3 \pm 5.1 \quad 80.7 \pm 5.0 \quad>0.05$
deICPEB

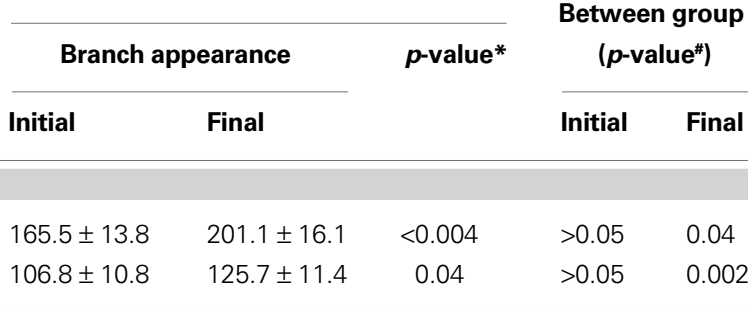

Comparisons made between a terminal branch's initial and final appearance in the time-lapse series. ${ }^{*}$ Indicates significant differences in punctum intensity between initial and final intensities measured with a paired t-test. \#Indicates significant differences in punctum intensity between neurons expressing full-length CPEB and de/CPEB measured with unpaired t-tests. $N=194$ and 285 for CPEB and delCPEB branches, respectively.

These data also indicate that when they are unable to regulate polyadenylation and translation normally, delCPEB-expressing neurons accumulate delCPEB protein in their RNP granules. A model proposed by Krichevsky and Kosik (2001) suggests that while assembled into RNP granules, mRNAs are compacted in the protein complex and translationally repressed. Their electron microscopic analysis of cultured cortical neurons showed that the neuronal depolarization that relieves translation inhibition also caused RNP granules to disappear and apparently disperse their contents. Once released from granules, the mRNA is thought to be accessible to the assembly of the translation initiation machinery (Krichevsky and Kosik, 2001). These results are consistent with the actions of the RNA binding protein RNG105 (Caprin1) in cultured hippocampal neurons. Shiina et al. (2005) found that the fluorescence intensity of RNG105-expressing RNP granules in decreased in response to stimulation while the level of a protein synthesis reporter increased at the same location in the dendritic arbor. A protein like CPEB, which has been shown to trigger polyadenylation-induced translation downstream of synaptic activity, is an excellent candidate to be used by RNP granules to transduce local signals and trigger the initiation of protein synthesis. Our results suggest that the RNP granules of cells expressing full-length CPEB have relatively consistent levels of protein over the course of the 60-min time-lapse period. In contrast, the RNP granules of
delCPEB-expressing neurons, rendered insensitive to synaptic signals by the deletion of CPEB's phosphorylation site, accumulate in the dendritic branches. In keeping with the Krichevsky and Kosik model and similar to the actions of RNG105 in cultured hippocampal neurons (Krichevsky and Kosik, 2001; Shiina et al., 2005), our data suggest that the RNP granules containing full-length $\mathrm{CPEB}$ continually release their contents for translation in response to local signals. An analysis that combines methods which reveal the localization of identified RNP granules with fluorescent reporters that provide measurements of their local protein synthesis (e.g., Aakalu et al., 2001; Shiina et al., 2005) will go a long way toward helping us understand local regulation of mRNA translation.

\section{ACKNOWLEDGEMENTS}

We thank Kimberly Bronson and Seung Yeon Lee for their excellent technical work and Dr. Joel Richter for plasmid reagents. The Fragile X Research Foundation, the Dana Foundation, Dart Neuroscience LLC, and the National Institute of Health (NEI EY011261 and DP1 OD000458) supported this work.

\section{SUPPLEMENTARY MATERIAL}

The Supplementary Material for this article can be found online at http://www.frontiersinneuroscience/neuralcircuits/paper/10.3389/ neuro.04/010.2009/ 


\section{REFERENCES}

Aakalu, G., Smith, W. B., Nguyen, N. Jiang, C., and Schuman, E. M. (2001). Dynamic visualization of local protein synthesis in hippocampal neurons. Neuron 30, 489-502.

Alarcon, J. M., Hodgman, R., Theis, M., Huang, Y. S., Kandel, E. R., and Richter, J. D. (2004). Selective modulation of some forms of Schaffer collateral-CA1 synaptic plasticity in mice with a disruption of the CPEB-1 gene. Learn. Mem. 11, 318-327.

Antar, L. N., Afroz, R., Dictenberg, J. B., Carroll, R. C., and Bassell, G. J. (2004). Metabotropic glutamate receptor activation regulates Fragile $\mathrm{X}$ mental retardation protein and Fmrl mRNA localization differentially in dendrites ad at synapses. J. Neurosci. 24, 2648-2655.

Antar,L.N.,Dictenberg,J.B.,Plociniak, M., Afroz, R., and Bassell, G. J. (2005). Localization of FMRP-associated mRNA granules and requirement of microtubules for activity-dependent trafficking in hippocampal neurons. Genes Brain Behav. 4, 350-359.

Bagni, C., Mannucci, L., Dotti, C. G., and Amaldi, F. (2000). Chemical stimulation of synaptosomes modulates alpha- $\mathrm{Ca}^{2+} /$ calmodulin-dependent protein kinase II mRNA association to polysomes. J. Neurosci. 20, RC76.

Berger-Sweeney, J., Zearfoss, N. R., and Richter, J. D. (2006). Reduced extinction of hippocampal-dependent memories in CPEB knockout mice. Learn. Mem. 13, 4-7.

Besse, F., and Ephrussi, A. (2008). Translational control of localized mRNAs: restricting protein synthesis in space and time. Nat. Rev. Mol. Cell Biol. 9, 971-980.

Bestman, J. E., and Cline, H. T. (2008). The RNA binding protein CPEB regulates dendrite morphogenesis and neuronal circuit assembly in vivo. Proc. Natl. Acad. Sci. USA 105, 20494-20499.

Bestman, J.E., Ewald, R. C., Chiu, S.L., and Cline, H. T. (2006). In vivo single-cell electroporation for transfer of DNA and macromolecules. Nat. Protoc. 1, 1267-1272.

Bramham, C. R., and Wells, D. G. (2007). Dendritic mRNA: transport, translation and function. Nat. Rev. Neurosci. $8,1-14$.

Carson, J. H., Gao, Y., Tatavarty, V., Levin, M. K., Korza, G., Francone, V. P., Kosturko, L. D., Maggipinto, M. J., and Barbarese, E. (2008). Multiplexed RNA trafficking in oligodendrocytes and neurons. Biochim. Biophys. Acta 1779, 453-458.

Cline, H. T. (2001). Dendritic arbor development and synaptogenesis. Curr. Opin. Neurobiol. 11, 118-126.
Cosma, M. P. (2004). Daughter-specific repression of Saccharomyces cerevisiae HO: Ash1 is the commander. EMBO Rep. 5, 953-957.

Cougot, N., Bhattacharyya, S. N., Tapia-Arancibia, L., Bordonne, R., Filipowicz, W., Bertrand, E., and Rage, F. (2008). Dendrites of mammalian neurons contain specialized P-body-like structures that respond to neuronal activation. J. Neurosci. 28, 13793-13804.

Dahm, R., Kiebler, M., and Macchi, P. (2007). RNA localisation in the nervous system. Semin. Cell Dev. Biol. 18, 216-223.

Dictenberg, J. B., Swanger, S. A., Antar, L. N., Singer, R. H., and Bassell, G. J. (2008). A direct role for FMRP in activity-dependent dendritic mRNA transport links filopodial-spine morphogenesis to fragile $\mathrm{X}$ syndrome. Dev. Cell 14, 926-939.

Doe, C. Q. (2008). Neural stem cells: balancing self-renewal with differentiation. Development 135, 1575-1587.

Du, L., and Richter, J. D. (2005). Activitydependent polyadenylation in neurons. RNA 11, 1340-1347.

Du, T. G., Schmid, M., and Jansen, R. P. (2007). Why cells move messages: the biological functions of mRNA localization. Semin. Cell Dev. Biol. 18 , 171-177.

Dynes, J. L., and Steward, O. (2007). Dynamics of bidirectional transport of Arc mRNA in neuronal dendrites. J. Comp. Neurol. 500, 433-447.

Ferrari, F., Mercaldo, V., Piccoli, G., Sala, C., Cannata, S., Achsel, T., and Bagni, C. (2007). The fragile X mental retardation protein-RNP granules show an mGluR-dependent localization in the post-synaptic spines. Mol. Cell. Neurosci. 34, 343-354.

Grooms, S. Y., Noh, K. M., Regis, R., Bassell, G. J., Bryan, M. K., Carroll, R. C., and Zukin, R. S. (2006). Activity bidirectionally regulates AMPA receptor mRNA abundance in dendrites of hippocampal neurons. J. Neurosci. 26, 8339-8351.

Hirokawa, N. (2006). mRNA transport in dendrites: RNA granules, motors, and tracks. J. Neurosci. 26, 7139-7142.

Hogan, D. J., Riordan, D. P., Gerber, A. P., Herschlag, D., and Brown, P. O. (2008). Diverse RNA-binding proteins interact with functionally related sets of RNAs, suggesting an extensive regulatory system. PLoS Biol. 6, e255. doi: 10.1371/journal. pbio. 0060255

Horton, A. C., Racz, B., Monson, E. E., Lin, A. L., Weinberg, R. J., and Ehlers, M. D. (2005). Polarized secretory trafficking directs cargo for asymmetric dendrite growth and morphogenesis. Neuron 48, 757-771.
Huang, Y. S., Carson, J. H., Barbarese, E., and Richter, J. D. (2003). Facilitation of dendritic mRNA transport by CPEB. Genes Dev. 17, 638-653.

Huang, Y. S., Jung, M. Y., Sarkissian, M. and Richter, J. D. (2002). $\mathrm{N}$-methyl-D-aspartate receptor signaling results in Aurora kinase-catalyzed CPEB phosphorylation and alpha CaMKII mRNA polyadenylation at synapses. EMBO J. 21, 2139-2148.

Keene, J.D. (2007). RNA regulons: coordination of post-transcriptional events Nat. Rev. Genet. 8, 533-543.

Kiebler, M. A., and Bassell, G. J. (2006) Neuronal RNA granules: movers and makers. Neuron 51, 685-690.

Knowles, R. B., and Kosik, K. S. (1997). Neurotrophin-3 signals redistribute RNA in neurons. Proc. Natl. Acad. Sci. USA 94, 14804-14808.

Knowles, R. B., Sabry,J.H., Martone, M. E., Deerinck, T. J., Ellisman, M. H., Bassell, G. J., and Kosik, K. S. (1996). Translocation of RNA granules in living neurons. J. Neurosci. 16, 7812-7820.

Krichevsky, A. M., and Kosik, K. S. (2001). Neuronal RNA granules: a link between RNA localization and stimulation-dependent translation. Neuron 32, 683-696.

Lange, S., Katayama, Y., Schmid, M. Burkacky, O., Brauchle, C., Lamb, D.C. and Jansen, R. P. (2008). Simultaneous transport of different localized mRNA species revealed by live-cell imaging. Traffic 9, 1256-1267.

Lecuyer, E., Yoshida, H., Parthasarathy, N. Alm, C., Babak, T., Cerovina, T., Hughes, T. R., Tomancak, P., and Krause, H. M. (2007). Global analysis of mRNA localization reveals a prominent role in organizing cellular architecture and function. Cell 131 , 174-187.

Li, J., Erisir, A., and Cline, H. T. (2007). Combined in vivo time lapse 2 photon imaging and ultrastructural analysis of synaptic dynamics in the Xenopus retinotectal system. Soc. Neurosci. Abstr. 34.4/D28.

Lin, A. C., and Holt, C. E. (2008). Function and regulation of local axonal translation. Curr. Opin. Neurobiol. 18 60-68.

McEvoy, M., Cao, G., Llopis, P. M., Kundel, M., Jones, K., Hofler, C., Shin, C., and Wells, D. G. (2007) Cytoplasmic polyadenylation element binding protein 1-mediated mRNA translation in Purkinje neurons is required for cerebellar long-term depression and motor coordination. J. Neurosci. 27, 6400-6411.

Mendez, R., and Richter, J. D. (2001). Translational control by CPEB: a means to the end. Nat. Rev. Mol. Cell Biol. 2, 521-529.
Mingle, L. A., Okuhama, N. N., Shi, J. Singer, R. H., Condeelis, J., and Liu, G. (2005). Localization of all seven messenger RNAs for the actin-polymerization nucleator Arp2/3 complex in the protrusions of fibroblasts. J. Cell Sci. 118, 2425-2433.

Miniaci, M. C., Kim, J. H. Puthanveettil, S. V., Si, K., Zhu, H., Kandel, E. R., and Bailey, C. H. (2008). Sustained CPEB-dependent local protein synthesis is required to stabilize synaptic growth for persistence of long-term facilitation in Aplysia. Neuron 59, 1024-1036.

Moore, M. J. (2005). From birth to death: the complex lives of eukaryotic mRNAs. Science 309, 1514-1518.

Niell, C. M., Meyer, M. P., and Smith, S. J. (2004). In vivo imaging of synapse formation on a growing dendritic arbor. Nat. Neurosci. 7, 254-260.

Pique, M., Lopez, J. M., Foissac, S., Guigo, R., and Mendez, R. (2008). A combinatorial code for CPE-mediated translational control. Cell 132, 434-448.

Richter, J. D. (2007). CPEB: a life in translation. Trends Biochem. Sci. 32, 279-285.

Rook, M. S., Lu, M., and Kosik, K. S. (2000). CaMKIIalpha 3' untranslated region-directed mRNA translocation in living neurons: visualization by GFP linkage. J. Neurosci. 20, 6385-6393.

Ruthazer, E. S., Li, J., and Cline, H. T. (2006). Stabilization of axon branch dynamics by synaptic maturation. J. Neurosci. 26, 3594-3603.

Sanchez-Carbente, M. R., and Desgroseillers, L. (2008). Understanding the importance of mRNA transport in memory. Prog. Brain Res. 169, 41-58.

Shepard, K.A., Gerber,A.P., Jambhekar, A., Takizawa, P. A., Brown, P. O., Herschlag, D., DeRisi, J. L., and Vale, R. D. (2003). Widespread cytoplasmic mRNA transport in yeast: identification of 22 bud-localized transcripts using DNA microarray analysis. Proc. Natl. Acad. Sci. USA 100, 11429-11434.

Shiina, N., Shinkura, K., and Tokunaga, M. (2005). A novel RNA-binding protein in neuronal RNA granules: regulatory machinery for local translation. J. Neurosci. 25, 4420-4434.

Sossin, W.S., and DesGroseillers, L. (2006). Intracellular trafficking of RNA in neurons. Traffic 7, 1581-1589.

St Johnston, D. (2005). Moving messages: the intracellular localization of mRNAs. Nat. Rev. Mol. Cell Biol. 6, 363-375.

Steward, O., and Schuman, E. M. (2003). Compartmentalized synthesis and degradation of proteins in neurons. Neuron 40, 347-359. 
Sutton, M.A., and Schuman, E. M. (2006). Dendritic protein synthesis, synaptic plasticity, and memory. Cell 127, 49-58.

Tiedge, H., and Brosius, J. (1996). Translational machinery in dendrites of hippocampal neurons in culture. J. Neurosci. 16, 7171-7181.

Tiruchinapalli, D. M., Oleynikov, Y., Kelic, S., Shenoy, S. M., Hartley, A., Stanton, P. K., Singer, R. H., and Bassell, G. J. (2003). Activitydependent trafficking and dynamic localization of zipcode binding protein 1 and beta-actin mRNA in dendrites and spines of hippocampal neurons. J. Neurosci. 23, 3251-3261.
Weiler, I. J., Irwin, S. A., Klintsova, A. Y. Spencer, C. M., Brazelton, A. D., Miyashiro, K., Comery, T. A., Patel, B., Eberwine, J., and Greenough, W. T. (1997). Fragile X mental retardation protein is translated near synapses in response to neurotransmitter activation. Proc. Natl. Acad. Sci. USA 94, 5395-5400.

Wilczynska, A., Aigueperse, C., Kress, M., Dautry, F., and Weil, D. (2005). The translational regulator $\mathrm{CPEB} 1$ provides a link between $\mathrm{dcp} 1$ bodies and stress granules. J. Cell Sci. 118, 981-992.

Wu, L., Wells, D., Tay, J., Mendis, D., Abbott, M.A., Barnitt,A., Quinlan, E., Heynen, A., Fallon, J. R., and
Richter, J. D. (1998). CPEB-mediated cytoplasmic polyadenylation and the regulation of experience-dependent translation of alpha-CaMKII mRNA at synapses. Neuron 21, 1129-1139.

Zhang, H. L., Eom, T., Oleynikov, Y., Shenoy, S. M., Liebelt, D. A. Dictenberg, J. B., Singer, R. H., and Bassell, G. J. (2001). Neurotrophininduced transport of a beta-actin mRNP complex increases beta-actin levels and stimulates growth cone motility. Neuron 31, 261-275.

Conflict of Interest Statement: The authors declare that the research was conducted in the absence of any commercial or financial relationships that could be construed as a potential conflict of interest.

Received: 02 June 2009; paper pending published: 30 June 2009; accepted: 15 August 2009; published online: 01 September 2009. Citation: Bestman JE and Cline HT (2009) The relationship between dendritic branch dynamics and CPEB-labeled RNP granules captured in vivo. Front. Neural Circuits 3:10. doi: 10.3389/neuro.04.010.2009 Copyright $(2009$ Bestman and Cline. This is an open-access article subject to an exclusive license agreement between the authors and the Frontiers Research Foundation, which permits unrestricted use, distribution, and reproduction in any medium, provided the original authors and source are credited. 